\title{
Uso de Peróxido de Hidrógeno como Enjuague Bucal Previo a la Consulta Dental para Disminuir la Carga Viral de COVID-19. Revisión de la Literatura
}

\author{
Use of Hydrogen Peroxide as a Dental Pre-consultation Mouthwash \\ to Decrease the Viral Load of COVID-19. Literature Review
}

Méndez, J.1,2 \& Villasanti, U. ${ }^{3}$

MÉNDEZ, J. \& VILLASANTI, U. Uso de peróxido de hidrógeno como enjuague bucal previo a la consulta dental para disminuir la carga viral de Covid-19. Revisión de la Literatura. Int. J. Odontostomat., 14(4):544-547, 2020.

RESUMEN: La utilización de enjuagues antisépticos previo a la atención odontológica favorecería la disminución del virus en la cavidad oral. Se ha planteado el uso de peróxido de hidrógeno preconsulta dental. Se revisaron las bases de datos PubMed, Cochrane y Elsevier publicados desde Enero 2019 a junio 2020. Los estudios que cumplieron los criterios de inclusión fueron revisados por 2 autores individualmente. Se realizó una revisión cualitativa de los datos. No existen ensayos controlados aleatorios o estudios de observación clínica sobre el efecto curativo o preventivo del peróxido de hidrógeno contra el COVID-19, pero si protocolos de ensayos clínicos que están en proceso de reclutamiento. El enjuague bucal con peróxido de hidrógeno podría ser una solución viable pre consulta dental que debe ser estudiada para reducir la carga viral del COVID-19.

PALABRAS CLAVE: peróxido de hidrógeno, COVID-19, enjuague bucal.

\section{INTRODUCCIÓN}

La utilización de enjuagues antisépticos previo a la atención odontológica favorecería la disminución del virus en la cavidad oral. Se ha planteado el uso de peróxido de hidrogeno preconsulta dental (Meng et al., 2020). Esto es importante debido a la cantidad de aerosoles que se generan durante una consulta dental.

Diversos agentes biocidas pueden inactivar al SARS-CoV y MERS-CoV de forma efectiva, estos son el etanol (alcohol etílico) $78 \%$ - $95 \%$ durante 30 segundos, 2-propanol (alcohol isopropílico) $70 \%$ $100 \%$ durante 30 segundos, formaldehido $0,7 \%-1$ $\%$ durante 2 minutos, povidona yodada $0,23 \%-7,5$ $\%$ durante 1 minuto. El glutaraldehído $2,5 \%$ durante 5 minutos o $0,5 \%$ durante 2 minutos inactiva al SARS-CoV, pero sin estudios para MERS-CoV. El hipoclorito de sodio requiere una concentración mínima de $0,21 \%$ durante 30 segundos para ser efec- tivo y el peróxido de hidrogeno una concentración de $0,5 \%$ durante un minuto, aunque estos resultados fueron con otros coronavirus y no MERS-CoV o SARS-CoV. La OMS recomienda utilizar hipoclorito de sodio $0,5 \%$ o alcohol etílico $70 \%$ durante, al menos, 1 minuto (Guiñez, 2020). También se ha recomendado estudiar los efectos preventivos de los enjuagues de biofilm orales terapéuticos con bCDCitrox para reducir la carga viral de la infección y posiblemente la progresión de la enfermedad (Carrouel et al., 2020).

El uso de un enjuague bucal contra el covid19 debe ser con elementos oxidativos, como la yodo povidona al $0,23 \%$ o peróxido de hidrógeno al $1 \%$. Se debe tener en cuenta que los enjuagues con clorhexidina, parecen no ser eficaces para matar al virus (González-Quintanilla \& Santos-López, 2020; Peng et al., 2020).

\footnotetext{
${ }^{1}$ Instituto Regional de Investigación en Salud, Universidad Nacional de Caaguazú, Paraguay.

${ }^{2}$ Facultad de Ciencias Médicas, Universidad de la Frontera, Temuco, Chile.

${ }^{3}$ Facultad de Odontología, Universidad Nacional de Caaguazú, Paraguay.
} 
Por lo tanto se planteó el objetivo de determinar el uso de enjuague oral con contenido de peróxido de para reducir la carga viral preconsulta dental.

\section{MATERIAL Y MÉTODO}

Se revisaron las bases de datos PubMed, Cochrane, y Elsevier. Se revisaron artículos publicados entre los años 2019 a 2020. Se utilizaron los términos de búsqueda: COVID-19, peróxido de hidrogeno, enjuague bucal, carga viral. Se realizó una revisión cualitativa de los datos.

Los estudios que cumplieron los criterios de inclusión (ensayos clínicos, estudios prospectivos y estudios observacionales) fueron revisados por 2 autores individualmente. (Se excluyeron estudios que no cumplían con la calidad metodológica). Se extrajeron los datos, primer autor, año de publicación, tipo de estudio, dosis de peróxido y tiempo de uso.

\section{RESULTADOS}

En la búsqueda se encontraron 108 estudios, que posteriormente al filtrado quedaron 15 estudios para la síntesis cualitativa (Fig. 1).
No se encontraron ensayos clínicos culminados, pero si en etapa de reclutamiento. Además se encontraron protocolos de revisiones sistemáticas (Tabla I).

Con respecto al uso de peróxido de hidrogeno se recomienda el uso superior al $0,5 \%$ entre 15 segundos a 1 minuto (Tabla II).

\section{DISCUSIÓN}

No existen ensayos controlados aleatorios o estudios de observación clínica sobre el efecto curativo o preventivo del peróxido de hidrógeno contra el COVID19 (Khan, 2020; University of California, 2020) - Full Text View - ClinicalTrials.gov, s. f.). Pero si protocolos de ensayos clínicos que están en proceso de reclutamiento. También existen protocolos de revisiones sistemáticas en Cochrane (Burton et al., 2020a,b,c).

Los estudios describen que se debe indicar al paciente que realice un enjuague bucal antimicrobiano previo a la atención dental con el objetivo de reducir la carga microbiana en la saliva (Martínez-Camus \& Yévenes-Huaiquinao, 2020). Un metaanálisis concluyó que su uso provocó una reducción promedio de un $68,4 \%$ de unidades formadoras de colonias en el aerosol dental (Guiñez, 2020). La clorhexidina, que se usa comúnmente como enjuague bucal en la práctica

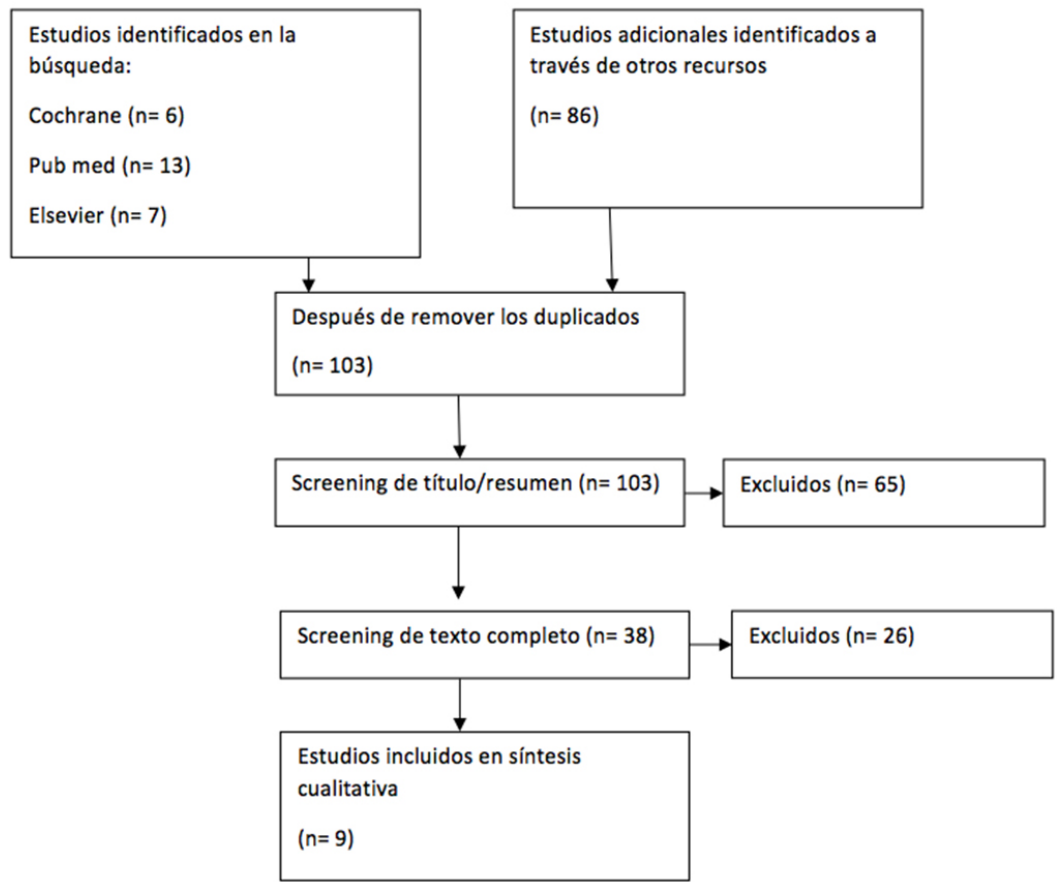

Fig. 1. Diagrama de flujo de revisión de estudios. 
MÉNDEZ, J. \& VILLASANTI, U. Uso de peróxido de hidrógeno como enjuague bucal previo a la consulta dental para disminuir la carga viral de Covid-19. Revisión de la Literatura. Int. J. Odontostomat., 14(4):544-547, 2020

Tabla I. Protocolos de Ensayos clínicos y Revisiones Sistemáticas publicadas $(n=5)$.

\begin{tabular}{|c|c|c|c|}
\hline Autor & $\begin{array}{l}\text { Tipo de estudio } \\
\text { propuesto }\end{array}$ & Objetivo & Enjuagues \\
\hline (Kazmi, 2020) & ECA & $\begin{array}{l}\text { Evaluar el efecto de tres soluciones antisépticas } \\
\text { de enjuague bucal / gárgaras de venta libre en } \\
\text { comparación œn un control (agua destilada) } \\
\text { para reducir la carga de SARS-CoV- } 2 \text {. }\end{array}$ & $\begin{array}{l}\text { lodo Povidona } 0,2 \% \text {, Peroxido de } \\
\text { Hidrógeno al } 1 \% \text {, extracto de neem, } \\
\text { solución salina, agua destilada }\end{array}$ \\
\hline $\begin{array}{l}\text { (Gansky \& Banava, } \\
\text { 2020) }\end{array}$ & $\mathrm{ECA}$ & $\begin{array}{l}\text { Identificar un enjuague antiviral contra el Covid- } \\
19\end{array}$ & $\begin{array}{l}\text { Peróxido de hidrógeno, } \\
\text { cloruro de cetilpiridinio, dióxido de cloro } \\
\text { estabilizado, agua destilada. }\end{array}$ \\
\hline Burton et al., 2020a & $\begin{array}{l}\text { Revision } \\
\text { Sistemática }\end{array}$ & $\begin{array}{l}\text { Evaluar los beneficios y los daños de los } \\
\text { enjuagues bucales antimicrobianos y los } \\
\text { aerosoles nasales administrados a los } \\
\text { trabajadores de la salud (PS) y / o pacientes al } \\
\text { realizar procedimientos de generación de } \\
\text { aerosol (AGP) en pacientes sin sospecha o } \\
\text { confirmación de infección por COVID-19. }\end{array}$ & $\begin{array}{l}\text { Cualquier enjuague bucal antimicrobiano } \\
\text { y / o aerosol nasal (solo o en } \\
\text { combinación) en cualquier } \\
\text { concentración, entregado al paciente o } \\
\text { al PS antes y / o después de un AGP. }\end{array}$ \\
\hline Burton et al., 2020a & $\begin{array}{l}\text { Revision } \\
\text { Sistemática }\end{array}$ & $\begin{array}{l}\text { Evaluar los beneficios y los daños de los } \\
\text { enjuagues bucales antimicrobianos y los } \\
\text { aerosoles nasales utilizados por los trabajadores } \\
\text { de la salud (PS) para protegerse al tratar a } \\
\text { pacientes con infección sospechada o } \\
\text { confirmada por COVID-19 }\end{array}$ & $\begin{array}{l}\text { Cualquier enjuague bucal antimicrobiano } \\
\text { y / o aerosol nasal (solo o en } \\
\text { combinación) en cualquier } \\
\text { concentración, administrado con } \\
\text { cualquier frecuencia o dosis a los PS, } \\
\text { con o sin la misma intervención } \\
\text { administrada a los pacientes con } \\
\text { COVID-19. }\end{array}$ \\
\hline Burton et al., 2020a & $\begin{array}{l}\text { Revision } \\
\text { Sistemática }\end{array}$ & $\begin{array}{l}\text { Evaluar los beneficios y los daños de los } \\
\text { enjuagues bucales antimicrobianos y los } \\
\text { aerosoles nasales administrados a pacientes } \\
\text { con infección sospechada o confirmada de } \\
\text { COVID-19 para proteger a los trabajadores de la } \\
\text { salud (HCW) que los atienden. }\end{array}$ & $\begin{array}{l}\text { Cualquier enjuague bucal antimicrobiano } \\
\text { y / o aerosol nasal (solo o en } \\
\text { combinación) a cualquier concentración, } \\
\text { administrado con cualquier frecuencia o } \\
\text { dosis a pacientes con sospecha / } \\
\text { confirmación de COVID-19. }\end{array}$ \\
\hline
\end{tabular}

dental, puede no ser efectiva matar 2019-nCoV (Peng et al.).

La literatura de estudios inmunológicos in vitro señala claramente que la aplicación de peróxido de hidrógeno en las células epiteliales de la nariz, la garganta y la boca puede ser extremadamente efectiva contra los virus, incluidos los coronavirus. (Caruso et al., 2020).

Se recomienda el uso de peróxido de hidrógeno en una dilución al $1 \%$ (Peng et al.). Para obtener $15 \mathrm{~mL}$ de enjuage, se puede utilizar $5 \mathrm{~mL}$ de peróxido de hidrógeno 10 Vol. adicionando $10 \mathrm{~mL}$ de agua destilada; también se ha descrito la utilización Povidona al 0,2\%. Estos antisépticos se han demostrado efectivos en la disminución de la carga viral salival y con baja posibilidad de complicaciones secundarias como estomatitis y úlceras de cavidad oral. Se ha recomen- dado el uso del peróxido por entre 15 a 30 segundos, también se recomendó por 1 minuto (Araya-Salas, 2020; Ather et al., 2020).

Existen en el mercado enjuagues bucales disponibles que contienen $1,5 \%$ de peróxido de hidrógeno que está por encima de la concentración recomendada de $0,5 \%$ requerida para ser virucida al coronavirus (Saravanamuttu, 2020). La evidencia es muy baja por lo que se recomiendan realizar estudios clínicos al respecto.

\section{CONCLUSIÓN}

El enjuague bucal con peróxido de hidrogeno podría ser una solución viable pre consulta dental para reducir la carga viral del COVID-19.

Tabla II. Dosis y Tiempo recomendados sobre el uso de peróxido de hidrogeno como enjuague bucal para reducir la carga viral del COVID-19.

\begin{tabular}{lcc}
\hline Autor & Tiempo recomendado & Dosis recomendada \\
\hline Ather et al., 2020. & no encontrado & 0,5 a 1\% \\
Caruso et al., 2020. & 1 minuto & $3 \%$ \\
Gansky \& Banava, 2020. & 15 segundos & $1 \%$ \\
Guiñez-Coelho, 2020 & 1 minuto & $0,5 \%$ \\
Kazmi, 2020. & $20-30$ segundos & $1 \%$ \\
Peng et al., 2020. & no encontrado & $1 \%$ \\
\hline
\end{tabular}


MÉNDEZ, J. \& VILLASANTI, U. Use of hydrogen peroxide as a dental pre-consultation mouthwash to decrease the viral load of COVID-19. Literature review. Int. J. Odontostomat., 14(4):544-547, 2020.

ABSTRACT: The use of antiseptic rinses prior to dental care would favor the reduction of the virus in the oral cavity. The use of hydrogen peroxide prior to dental consultation has been proposed. PubMed, Cochrane and Elsevier databases published from January 2019 to June 2020 were reviewed. Studies that met the inclusion criteria were reviewed by 2 authors individually. A qualitative review of the data was performed. There are no randomized controlled trials or clinical observation studies on the curative or preventive effect of hydrogen peroxide against COVID-19, but there are clinical trial protocols that are in the process of recruitment. Hydrogen peroxide mouthwash could be a viable solution prior to dental consultation that should be studied, to reduce COVID-19 viral load .

\section{mouthwash}

KEYWORDS: hydrogen peroxide, COVID-19,

\section{REFERENCIAS BIBLIOGRÁFICAS}

Araya-Salas, C. Considerations for emergency dental care and preventive measures for COVID-19 (SARS-CoV 2). Int. J. Odontostomat., 14(3):268-70, 2020.

Ather, A.; Patel, B.; Ruparel, N. B.; Diogenes, A. \& Hargreaves, K. M. Coronavirus Disease 19 (COVID-19): implications for clinical dental care. J. Endod., 46(5):584-95, 2020

Burton, M. J.; Clarkson, J. E.; Goulao, B.; Glenny, A. M.; McBain, A. J.; Schilder, A. G. M.; Webster, K. E. \& Worthington, H. V. Antimicrobial mouthwashes (gargling) and nasal sprays administered to patients with suspected or confirmed COVID-19 infection to improve patient outcomes and to protect healthcare workers treating them. Cochrane Database Syst. Rev., (5):CD013627, 2020a. DOI: https://www.doi.org/10.1002/ 14651858.CD013627

Burton, M. J.; Clarkson, J. E.; Goulao, B.; Glenny, A. M.; McBain, A. J.; Schilder, A. G. M.; Webster, K. E. \& Worthington, H. V. Antimicrobial mouthwashes (gargling) and nasal sprays to protect healthcare workers when undertaking aerosol-generating procedures (AGPs) on patients without suspected or confirmed COVID-19 infection. Cochrane Database Syst. Rev., (5):CD013628, 2020b. DOI: https://www.doi.org/10.1002/ 14651858.CD013628

Burton, M. J.; Clarkson, J. E.; Goulao, B.; Glenny, A. M.; McBain, A. J.; Schilder, A. G. M.; Webster, K. E. \& Worthington, H. V. Use of antimicrobial mouthwashes (gargling) and nasal sprays by healthcare workers to protect them when treating patients with suspected or confirmed COVID-19 infection. Cochrane Database Syst. Rev., (5): CD013626, 2020c. DOI: https://www.doi.org/ 10.1002/ 14651858.CD013626

Carrouel, F.; Conte, M. P.; Fisher, J.; Gonçalves, L. S.; Dussart, C.; Llodra, J. C. \& Bourgeois, D. COVID-19: a recommendation to examine the effect of mouthrinses with b-cyclodextrin combined with citrox in preventing infection and progression. J. Clin. Med., 9(4):1126, 2020.

Caruso, A. A.; Del Prete, A. \& Lazzarino, A. I. Hydrogen peroxide and viral infections: A literature review with research hypothesis definition in relation to the current covid-19 pandemic. Med. Hypotheses, 144:109910, 2020.

González-Quintanilla, D. \& Santos-López, M. Preventive measures and considerations for oral surgery practice during COVID-19. Int. J. Odontostomat., 14(3):338-41, 2020.

Guiñez, C. M. Impact of COVID-19 worldwide, implications and preventive measures in dental practice and its psychological consequences on patients. Int. J. Odontostomat., 14(3):271-8, 2020.

Khan, F. R. A Clinical Trial of Gargling Agents in Reducing Intraoral Viral Load Among COVID-19 Patients (GARGLES). In: ClinicalTrials.gov. Bethesda, U. S. National Library of Medicine, 2020. Disponible en: https://clinicaltrials.gov/ct2/show/ NCT04341688

Martínez-Camus, D. C. \& Yévenes-Huaiquinao, S. R. Dental care during COVID-19 pandemic. Int. J. Odontostomat., 14(3):288-95, 2020.

Meng, L.; Hua, F. \& Bian, Z. Coronavirus Disease 2019 (COVID-19): emerging and future challenges for dental and oral medicine. $J$. Dent. Res., 99(5):481-7, 2020.

Peng, X.; Xu, X.; Li, Y.; Cheng, L.; Zhou, X. \& Ren, B. Transmission routes of $2019-\mathrm{nCoV}$ and controls in dental practice. Int. J. Oral Sci., 12(1):9, 2020.

Saravanamuttu, R. Hydrogen peroxide mouthwash. Br. Dent. J., 228:734, 2020.

University of California. Antiseptic Mouthwash / Pre-Procedural Rinse on SARS-CoV-2 Load (COVID-19) (AMPoL). In: ClinicalTrials.gov. Bethesda, U. S. National Library of Medicine, 2020. Disponible en: https://clinicaltrials.gov/ct2/show/NCT04409873

\section{Dirección para correspondencia:}

Julieta Méndez

Instituto Regional de Investigación en Salud

Tuyuti y Mariscal Estigarribia

Coronel Oviedo

PARAGUAY

Email: julieta_mendez92@hotmail.com

Recibido: 17-06-2020

Aceptado:20-07-2020 